\title{
Evaluation of oxidative and antioxidant markers in the blood samples of patients with abdominal aorta pathology
}

\author{
Fevzi Sarper Türker' ${ }^{10}$, Mine Erişir² ${ }^{2}$ \\ ${ }^{1}$ Department of Cardiovascular Surgery, Elazlğ Fethi Sekin City Hospital, Elazığ, Turkey \\ ${ }^{2}$ Department of Biochemistry, Firat University Faculty of Veterinary Medicine, Elazl ̌̆, Turkey
}

\begin{abstract}
Objectives: This study aims to investigate the effects of oxidative damage on the development of the disease in patients scheduled for surgery for aortoiliac occlusive disease (AOD) and abdominal aortic aneurysm (AAA).

Patients and methods: Between June 2015 and July 2016, a total of 24 patients ( 22 males, 2 females; mean age $63.2 \pm 10.4$ years; range, 41 to 76 years) who admitted to our clinic for surgery were included in the study. The study group consisted of all elective AOD and AAA patients. The control group $(\mathrm{n}=100)$ consisted of healthy volunteers including health care personnel, particularly physicians working in the hospital. We obtained blood samples before surgery and compared levels of malondialdehyde (MDA) as an indicator of oxidative damage, and the levels of certain antioxidant enzymes such as superoxide dismutase (SOD), catalase (CAT) and reduced glutathione (GSH) with the blood levels of healthy volunteers.

Results: The comparison of the patient and healthy volunteer groups showed that blood MDA levels increased due to the oxidative damage $(\mathrm{p}=0.001)$. Regarding the antioxidant activity, we found that GSH levels increased in the patient group; however, the SOD activity remained unchanged. The CAT activity was statistically significantly decreased in the patient group $(\mathrm{p}=0.001)$.

Conclusion: The increased oxidative damage levels (MDA) in all patient groups compared to healthy individuals may indicate that oxidative stress has an important role in the development of the disease. In the light of these results, we conclude that the GSH activity is not sufficient to compensate the existing damage and the low CAT activity in all groups may show that it has a role in the development of the disease.
\end{abstract}

Keywords: Abdominal aortic aneurysm, aortoiliac occlusive disease, catalase, malondialdehyde, superoxide dismutase.

The oxidative stress is the pathogenic mediator of several disorders, primarily cardiovascular diseases such as atherosclerosis and hypertension. It is also related to the development of abdominal aortic aneurysm (AAA). Some authors have suggested that oxidative stress may have a key role in the pathogenesis of AAA and antioxidant therapy can be considered for the delay of the development of an aneurysm..$^{[1,2]}$

During the oxidative stress, secondary tissue damage occurs due to the excessive production or destruction of reactive oxygen species (ROS). The balance between the production and destruction of ROS depends not only on the activation of ROS-generating systems such as nicotinamide adenine dinucleotide phosphate (NADPH) oxidase, but also on endogenous cellular antioxidants and on the activity of antioxidant enzymes such as superoxide dismutase (SOD), catalase (CAT), glutathione peroxidase $(\mathrm{GPx})$, glutathione reductase (GR), reduced glutathione (GSH), and thioredoxin. ${ }^{[3-5]}$ The ROS is associated with certain pathophysiological mechanisms, leading to the development of occlusive disorders. These mechanisms consist of peroxidation of lipids such as low-density lipoproteins, the increase in the endothelial dysfunction and inflammatory and prothrombotic activity, the stimulation of the smooth muscle cell proliferation, and vascular apoptosis. ${ }^{[6]}$ In AAA, ROS may induce the inflammatory response

Received: February 14, 2019 Accepted: May 30, 2019 Published online: July 05, 2019

Correspondence: Fevzi Sarper Türker, MD. Elazı̆̆ Fethi Sekin Şehir Hastanesi Kalp ve Damar Cerrahisi Kliniğgi, 23280 Elazı̆̆g, Turkey e-mail: sarperturker@gmail.com 
and activate matrix metalloproteinases which lead to the aortic degeneration. ${ }^{[7]}$

Aortoiliac occlusive disease (AOD) and AAA are complex disorders, which affect particularly elderly people and develop as a result of similar risk factors. ${ }^{[8,9]}$ Patients with AOD are prone to severe ischemia and are at risk for limb amputations due to progressive arterial insufficiency. ${ }^{[10]}$ Previous reports have shown that the development of AAA is associated with advanced age, male gender, smoking, and hypertension. ${ }^{[11,12]}$ In a recent study, it has been demonstrated that nicotine, which is the primary component of cigarette smoke, is strongly associated with AAA development and/or rupture. ${ }^{[13]}$ The correlation between the drug treatment and the development and rupture of AAA has not been elucidated, yet. ${ }^{[14]}$

Although AOD and AAA have different pathophysiological mechanisms, experimental studies have demonstrated that ROS and inflammatory response plays a key role in the development of both disorders. However, there is a very limited number of human studies on this topic. ${ }^{[15]}$

In the present study, we aimed to investigate the role of oxidative stress in aortic aneurysm and occlusive disorders in patients who were smokers or were ex-smokers. Therefore, we aimed to compare the indicators of the oxidative damage and antioxidant parameters in patients with those in healthy volunteers to delineate their role in the development and compensation of these disorders.

\section{PATIENTS AND METHODS}

This prospective study included a total of 24 patients (22 males, 2 females; mean age $63.2 \pm 10.4$ years; range, 41 to 76 years) who were admitted to our clinic for surgery between June 2015 and July 2016. The study group consisted of all elective AOD and AAA patients. Emergency cases such as ruptured AAAs and chronic renal insufficiency were excluded. The control group $(n=100)$ consisted of healthy volunteers including health care personnel, particularly physicians working in the hospital. The study group was divided into two groups as smokers $(n=35$; mean age $36.6 \pm 10.4$ years $)$ and non-smokers $(n=65$; mean age $38.7 \pm 9.5$ years). A written informed consent was obtained from each participant. The study protocol was approved by the Ethics Committee of Firat University, Faculty of Medicine (No. 2015-15). The study was conducted in accordance with the principles of the Declaration of Helsinki.
Blood samples were obtained from each patient before the surgical intervention (preoperative period). Following a briefing of the participants in the control group about the study, we took a brief anamnesis with physical examination and we obtained blood samples from each of them. In order to obtain a closer mean age in the control group, we comprised another control group with volunteers over age 45 (mean age $52.1 \pm 6.0$ years). A total of 24 patients with abdominal aorta disorders ( $n=8$ AOD; $n=3$ Leriche syndrome and $n=5$ atherosclerosis $+n=16$ AAA) were compared with the control group ( $\mathrm{n}=35$ smoker; $\mathrm{n}=65$ non-smoker; $\mathrm{n}=30$ age $\geq 45$ years).

Once blood samples were transferred in two heparin-containing test tubes with the cannula, which was inserted in the radial artery, they were sent to the laboratory for invasive blood pressure monitoring. One of the heparinized blood samples was used for complete blood count and the other sample was centrifuged at 3,000 rpm for five min for the separation of plasma. Then, the samples were washed three times with physiological saline solution. After the completion of the process, the samples were stored in the deep freezer at $-80^{\circ} \mathrm{C}$ until biochemical analyses.

Blood samples were used for the analysis of biochemical parameters such as malondialdehyde (MDA), an oxidative damage indicator, and GSH, CAT, and SOD as antioxidant indicators. The blood analyses of all patients and volunteers were performed manually in the laboratories of the Department of Biochemistry in the Veterinary School at Firat University, Elazig, Turkey.

All patients were either diagnosed in the clinic of cardiovascular surgery and scheduled for a surgery or patients or admitted to other clinics, primarily cardiology. All patients underwent computed tomography angiography during the planning of the surgery.

\section{Biochemical analyses}

\section{Lipid peroxidation}

The measurement of MDA in plasma was carried out with the method described by Placer et al. ${ }^{[16]}$ (slightly modified). Malondialdehyde formed a pinkcolored complex with thiobarbituric acid (TBA) and the absorbance read was at $532 \mathrm{~nm}^{\left[{ }^{[16]}\right.}$ The plasma MDA levels were given in $\mathrm{nmol} / \mathrm{mL}$.

\section{Glutathione}

The GSH levels were determined according to the method described by Chavan et al. ${ }^{[17]}$ GSH levels were given in $\mu \mathrm{mol} / \mathrm{gHb}$. 


\begin{tabular}{|c|c|c|c|c|c|c|c|c|c|c|c|c|}
\hline & \multicolumn{2}{|c|}{$\begin{array}{l}\text { A0D patients } \\
\quad(\mathrm{n}=8)\end{array}$} & \multicolumn{2}{|c|}{$\begin{array}{l}\text { AAA patients } \\
\quad(\mathrm{n}=16)\end{array}$} & \multicolumn{2}{|c|}{$\begin{array}{l}\text { Total abdominal } \\
\text { aorta patients } \\
(\mathrm{n}=24)\end{array}$} & \multicolumn{2}{|c|}{$\begin{array}{c}\text { Control group } \\
\text { non-smokers } \\
(\mathrm{n}=65)\end{array}$} & \multicolumn{2}{|c|}{$\begin{array}{c}\text { Control group } \\
\text { smokers } \\
(\mathrm{n}=35)\end{array}$} & \multicolumn{2}{|c|}{$\begin{array}{c}\text { Control group } \\
\text { age } \geq 45 \\
(\mathrm{n}=30)\end{array}$} \\
\hline & $\mathrm{n}$ & Mean $\pm S D$ & $\mathrm{n}$ & Mean \pm SD & $\mathrm{n}$ & Mean \pm SD & $\mathrm{n}$ & Mean \pm SD & $\mathrm{n}$ & Mean \pm SD & $\mathrm{n}$ & Mean $\pm S D$ \\
\hline Mean age (year) & & $53 \pm 8.16$ & & $68.3 \pm 7.2$ & & $63.2 \pm 10.4$ & & $38.7 \pm 9.5$ & & $36.6 \pm 10.4$ & & $52.1 \pm 6.0$ \\
\hline $\begin{array}{l}\text { Age (year) } \\
\text { Youngest } \\
\text { Oldest }\end{array}$ & $\begin{array}{l}41 \\
59\end{array}$ & & $\begin{array}{l}54 \\
76\end{array}$ & & $\begin{array}{l}41 \\
76\end{array}$ & & $\begin{array}{l}18 \\
67\end{array}$ & & $\begin{array}{l}18 \\
68\end{array}$ & & $\begin{array}{l}45 \\
68\end{array}$ & \\
\hline Diabetes mellitus & 2 & & - & & 2 & & 3 & & 3 & & 6 & \\
\hline COPD & 2 & & 10 & & 12 & & - & & - & & - & \\
\hline Hypertension & 6 & & 12 & & 18 & & 3 & & 1 & & 3 & \\
\hline $\begin{array}{l}\text { Gender } \\
\quad \text { Female } \\
\text { Male }\end{array}$ & $\begin{array}{l}2 \\
6\end{array}$ & & $\begin{array}{c}0 \\
16\end{array}$ & & $\begin{array}{c}2 \\
22\end{array}$ & & $\begin{array}{l}40 \\
25\end{array}$ & & $\begin{array}{l}14 \\
21\end{array}$ & & $\begin{array}{l}16 \\
14\end{array}$ & \\
\hline Smoking & 8 & & 10 & & 18 & & - & & 35 & & 6 & \\
\hline
\end{tabular}

AOD: Aortoiliac occlusive disease; AAA: Abdominal aortic aneurysm; SD: Standard deviation; COPD: Chronic obstructive pulmonary disease.

\section{CAT}

The Aebi method was used to measure the CAT activity. The degradation rate of $\mathrm{H}_{2} \mathrm{O}_{2}$ by CAT was spectrophotometrically measured by means of $\mathrm{H}_{2} \mathrm{O}_{2}$ absorbing light at a wavelength of $240 \mathrm{~nm} \cdot{ }^{[18]}$ The CAT activity was calculated in katal/gHb.

\section{$S O D$}

Superoxide dismutase activity, the SOD enzyme activity measurement was based on the degradation of nitro blue tetrazolium (NBT) by the superoxide radical, which was produced by the xanthine-xanthine oxidase system. The blue farmozan obtained at the end of the reactions was maximally absorbed at $560 \mathrm{~nm} .^{[19]}$ The SOD enzyme activity was calculated in $\mathrm{U} / \mathrm{gHb}$.

\section{Statistical analysis}

Statistical analysis was performed using Minitab for Windows version 17.0. Descriptive data were expressed in mean \pm standard deviation (SD) or number and frequency. One-way analysis of variance (ANOVA) was used to analyze data sets. A $p$ value of $<0.05$ was considered statistically significant.

\section{RESULTS}

Baseline demographic and clinical characteristics are shown in Table 1.

Oxidative damage and antioxidant parameters of smoker patients and controls are summarized in Table 2 . While reporting the results of statistical analysis, both

\begin{tabular}{|c|c|c|c|c|c|c|}
\hline Parameters & Group & $\mathrm{n}$ & Mean & SE mean & $p$ & ETA-squared $(\%)$ \\
\hline \multirow[t]{2}{*}{ Malondialdehyde } & 2 & 35 & 1.28 & 0.08 & & \\
\hline & 1 & 24 & 2.58 & 0.19 & 0.001 & 45.65 \\
\hline \multirow[t]{2}{*}{ Glutathione } & 2 & 35 & 1.05 & 0.04 & & \\
\hline & 1 & 24 & 16.37 & 2.30 & 0.001 & 53.29 \\
\hline \multirow[t]{2}{*}{ Catalase } & 2 & 35 & 230.27 & 9.97 & & \\
\hline & 1 & 24 & 28.49 & 4.35 & 0.001 & 81.82 \\
\hline \multirow[t]{2}{*}{ Superoxide dismutase } & 2 & 35 & 34.59 & 1.12 & & \\
\hline & 1 & 24 & 33.07 & 1.92 & 0.468 & 0.93 \\
\hline
\end{tabular}

AAA: Abdominal aortic aneurysm; AOD: Aortoiliac occlusive disease; SE: Standard error. 


\begin{tabular}{|c|c|c|c|c|c|c|}
\hline Parameters & Group & $\mathrm{n}$ & Mean & SE mean & $p$ & ETA-squared $(\%)$ \\
\hline \multirow[t]{2}{*}{ Malondialdehyde } & 2 & 64 & 1.12 & 0.05 & & \\
\hline & 1 & 24 & 2.58 & 0.19 & 0.001 & 50.83 \\
\hline \multirow[t]{2}{*}{ Glutathione } & 2 & 64 & 0.88 & 0.03 & & \\
\hline & 1 & 23 & 17.01 & 2.31 & 0.001 & 60.76 \\
\hline \multirow[t]{2}{*}{ Catalase } & 2 & 64 & 190.58 & 8.44 & & \\
\hline & 1 & 20 & 31.28 & 5.01 & 0.001 & 56.58 \\
\hline \multirow[t]{2}{*}{ Superoxide dismutase } & 2 & 64 & 32.31 & 05.83 & & \\
\hline & 1 & 24 & 33.07 & 1.92 & 0.334 & 1.14 \\
\hline
\end{tabular}

$p$ values indicating the statistical significance and ETA-squared indicating practical significance were reported. ${ }^{[20]}$ Statistically significant differences were observed between the patient and healthy volunteer smokers groups in terms of MDA, GSH, and CAT (Table 2; $\mathrm{p}=0.001$ ). For SOD parameter, on the other hand, the difference between the groups was not found to be significant $(p=0.468)$. When the practical significance of the observed differences was evaluated, the highest ETA-squared value was observed for CAT $(81.82 \%)$, indicating that the majority of the variations in CAT values could be explained according to the groups. In other words, the group was an important factor which could explain $81.82 \%$ of variation in CAT.

Table 3 shows the oxidative damage and antioxidant parameters of non-smoker patients and controls. There were statistically significant differences between the patient and healthy volunteer non-smokers groups in terms of MDA, GSH, and CAT (Table 3; p=0.001). For SOD parameter, on the other hand, the difference between the groups was not found to be significant $(p=0.334)$. When practical significance of the observed differences was evaluated, the highest ETA-squared value was observed for GSH (60.76\%).

Table 4 shows the oxidative damage and antioxidant parameters of patients and controls according to age $\geq 45$ years. Statistically significant differences were observed between the patient and healthy volunteers aged $\geq 45$ years in terms of MDA, GSH, and CAT (Table 4; $\mathrm{p}=0.001$ ). For SOD parameter, on the other hand, the difference between the groups was not found to be significant $(p=0.555)$. When the practical significance of the observed differences was evaluated, the highest ETA-squared value was observed for CAT (84.87\%).

When both patient groups were compared, MDA and SOD values were significant in terms of $p$ value, while they were practically not significant, since the ETA-square values were very low. When the patient groups alone were compared with healthy individuals,

\begin{tabular}{|c|c|c|c|c|c|c|}
\hline Parameters & Group & $\mathrm{n}$ & Mean & SE mean & $p$ & ETA-squared (\%) \\
\hline \multirow[t]{2}{*}{ Malondialdehyde } & 2 & 30 & 1.24 & 0.08 & & \\
\hline & 1 & 24 & 2.58 & 0.19 & 0.001 & 47.14 \\
\hline \multirow[t]{2}{*}{ Glutathione } & 2 & 30 & 1.05 & 0.04 & & \\
\hline & 1 & 24 & 16.37 & 2.30 & 0.001 & 51.63 \\
\hline \multirow[t]{2}{*}{ Catalase } & 2 & 30 & 231,0 & 10,0 & & \\
\hline & 1 & 24 & 28.49 & 4.35 & 0.001 & 84.87 \\
\hline \multirow[t]{2}{*}{ Superoxide dismutase } & 2 & 30 & 34.35 & 1.18 & & \\
\hline & 1 & 24 & 33.07 & 1.92 & 0.56 & 0.67 \\
\hline
\end{tabular}

AAA: Abdominal aortic aneurysm; AOD: Aortoiliac occlusive disease; SE: Standard error. 
the results were evaluated not to be significant enough in the variance analysis due to the small sample size.

\section{DISCUSSION}

The increase in ROS production, which depends on metabolic factors such as NADPH oxidase and myeloperoxidase (MPO), and the decrease in the antioxidant defense mechanisms such as SOD and CAT may lead to tissue damage. ${ }^{[21]}$ Oxidative stress is associated with pathogenic processes such as atherosclerosis and aneurysmal diseases, leading to tissue damage. ${ }^{[22,23]}$ In addition, the increase in ROS production may induce a proinflammatory process in vascular structures and lead to the accumulation of the inflammatory cells. ${ }^{[2]}$ Furthermore, it is associated with nitric oxide (NO), which is a biological mediator in the cardiovascular system, and several vascular disorders including peripheral arterial disease and AAA. ${ }^{[25,26]}$ Lucas et al. ${ }^{[15]}$ compared the aortic tissue samples obtained from AOD and/or AAA patients who underwent open abdominal surgery with the healthy aortic tissue obtained from cadaveric organ donors. The authors reported that the aortic ROS levels were significantly higher in the patient group, compared to the control group $(\mathrm{p}<0.001)$. In our study, we compared a total of 24 patients, who had abdominal aorta disease due to the smoking, with healthy control groups consisting of smokers, non-smokers, and volunteers aged $\geq 45$ years. The main goal of evaluation of these two diseases of the abdominal aorta together is to elucidate that smoking is a common factor in the development of both diseases. The reason for determining three separate groups in the control group is to approximate the smoking and age factors that play a role in oxidative damage to the patient group as far as possible. ${ }^{[27]}$ We compared the groups for oxidative damage and found statistically and practically significantly higher MDA levels in the patient group, indicating that it may be associated with the damage caused by the oxidative stress during the development of both diseases.

There are several endogenous antioxidant systems in the body which protect against the destructive processes caused by excessive ROS. These processes may be enzymatic such as SOD and CAT or nonenzymatic including vitamin $\mathrm{E}$ and vitamin $\mathrm{C}$. It has been already shown that SOD, which is the enzyme responsible for the removal of $\mathrm{O}^{2}$ (superoxide radical), has a protective effect against the atherosclerotic process. ${ }^{[28]}$
It has been well-established that three distinct types of SOD isoforms are expressed in mammalian tissues. ${ }^{[29]}$ The SOD1 (copper/zinc-SOD) is found in the cytoplasm and mitochondrial intermembrane space. ${ }^{[21]}$ The SOD2 is found in the mitochondrial matrix. ${ }^{[25]}$ The SOD3 is found in the extracellular matrix, on the cell surface, and in the extracellular fluids. ${ }^{\left[{ }^{30]}\right.}$ All three isoenzymes serve key antioxidant functions by catalyzing the dismutation of superoxide into oxygen and hydrogen peroxide. ${ }^{[31]} \mathrm{A}$ moderate SOD1 upregulation decreases the ROS burden, while extensively increased SOD activity can expand the oxidative damage by increasing the distal antioxidant activity. The SOD1 overexpression generates a high amount of hydrogen peroxide, which can lead to the formation of pro-atherogenic molecules, such as hydroxyl radicals or metal-associated reactive species. ${ }^{[28]}$ The SOD2 is the first defensive enzyme against superoxide, the by-product of the mitochondrial transport chain. Homozygous SOD2 mutant mice die within the first 10 days after birth, indicating the importance of this enzyme. ${ }^{[32]}$ However, the SOD3 isoform is strongly expressed on the vascular wall and its functional importance in the development of atherosclerosis has not been clarified, yet. ${ }^{[28]}$

In their study, Lucas et al. ${ }^{[15]}$ found that the SOD activity was also higher in the AAA and AOD groups, compared to the control group. The aortic fragments from the AOD group had higher SOD activity than the AAA group $(59.6 \pm 8.7$ vs. $42.8 \pm 6.7 \mathrm{U} / \mathrm{mg}$ of protein; $\mathrm{p}<0.001)$. In another study, the aforementioned authors compared the aortic tissues, which were obtained from AOD patients (severe stenosis or occlusion) with the aortic tissues obtained from cadaveric organ donors. ${ }^{[33]}$ They reported that, in addition to the ROS levels, the SOD and CAT activities also significantly increased in the patients compared to the control group $(\mathrm{p}<0.05)$. In this study, the authors concluded that the antioxidant enzyme activity increased to compensate the increased ROS levels, depending on the NADPHoxidase activity.

In the literature, there are several studies involving human subjects and showing a decline in the activity of antioxidant enzymes in the aorta of AOD and AAA patients. In a relatively earlier study conducted by Dubick et al., ${ }^{[24]}$ the authors compared the nonatherosclerotic aortic tissues obtained from organ donors with the aortic tissue samples (ruptured or non-ruptured) obtained from AAA and AOD patients. They observed that the SOD1 activity was $16 \%$ in the AAA group and $25 \%$ in the AOD group, 
compared to the controls. On the other hand, the SOD2 (Mn-SOD) level was 65\% in the aorta of the patients, compared to the controls. These findings indicated that lipid peroxidation increased in the aorta of AOD and AAA patients. ${ }^{[24]}$ We believe that although this study was earlier and the studies on blood levels are more significant since postmortem intracellular lytic enzymes and bacterial enzymes could affect the enzyme levels at tissue level in studies conducted on cadaveric tissues. ${ }^{[34]}$ Yajima et al. ${ }^{[35]}$ also reported that several pathways, which were responsible for the stimulation of ROS formation, supported the development of AAA and suggested that ROS inhibitors could decrease the size of the aneurysm in AAA patients.

In another study, Kugo et al. ${ }^{[36]}$ suggested that sesame extract suppressed the degradation of collagen and elastin fibers due to the decrease in MMP-12 expression and oxidative stress in a nicotineadministered mice model. Thus, they came to a speculative conclusion and suggested that sesamolin in sesame and sesame extract might inhibit the nicotinecaused oxidative stress and inflammation in vascular walls.

All these studies and our study demonstrated that oxidative damage was significantly higher, compared to the control group, during the development of AOD and AAA independent from the (decreased or increased) SOD activity at the tissue level. The comparison of the enzyme SOD, which is primarily effective in the compensation of oxidative stress, in patient and control groups did not indicate any statistically significant difference. This finding may depend on the enzyme SOD, which was not sufficiently increased during the development of the disease. Nevertheless, the correlation between the blood levels of the antioxidant enzymes and the antioxidant activity at the tissue level is still under discussion.

Catalases convert hydrogen peroxide into water and oxygen. They are found in peroxisomes and had a positive effect on atherosclerosis in high-fat diet mice models. ${ }^{[37]}$ Based on the type of atherosclerotic model examined, different effects of antioxidant enzymes were observed during the development of atherosclerosis. In the studies conducted with Apo-E KO mice (Apolipoprotein E knock out mice), it was suggested that atherogenic stimulation mostly developed due to the accumulation of peroxides. This process of the peroxide accumulation is ameliorated, at least in part, by catalases. ${ }^{[38]}$ Overexpression of the catalases improved atherosclerosis in Apo-E $\mathrm{KO}$ mice. ${ }^{[37]}$
Furthermore, in this mouse model, it was shown that SOD1 overexpression was ineffective, while catalases had a positive effect on atherosclerosis, if a highfat diet was provided. ${ }^{[37,39]}$ Besides atherosclerosis, CAT enzyme activity has also a protective effect on AAA. Experimental studies showed that CAT activity decreased the arterial damage. Parastatidis et al. ${ }^{[2]}$ reported in their experimental study that the decreased CAT activity in aortic walls might cause a predisposition to the development of AAA. The preservation of the CAT activity might protect against the AAA formation as a result of the modulation of the matrix metalloproteinase activity and the increase of the vascular smooth muscle cell survival.

In their study, Lucas et al. ${ }^{[15]}$ showed that the CAT activity was also higher in the AOD and AAA groups, compared to the control group. However, CAT activity in the aorta of patients with AAA was statistically higher than that in the AOD group $(120.3 \pm 28.6$ vs. $53.4 \pm 11.4 \mathrm{U} / \mathrm{mg}$ protein; $\mathrm{p}<0.001) .^{[15]}$ In our study, we found a significant decline in the CAT activity in the blood in all study groups. The antioxidant CAT activity might be not sufficient for the compensation of the existing damage and the increase in ROS levels. Thus, it might be responsible for the damage in the vascular wall related to ROS. Lucas et al. ${ }^{[15]}$ suggested that the increased SOD and CAT activities in the vascular wall might be responsible for the compensation of the increased ROS activity. The significant decrease in the CAT activity in the blood may lead to the development of the disease. However, further studies are needed to find out whether the cause of this decreased level is congenital or acquired.

Glutathione is a tripeptide thiol found in all cells. It has a critical and protective role against free radicals and ROS in various tissues. ${ }^{[40]}$ In the study by Tsan et al., ${ }^{[41]}$ it was reported that the GSH concentrations increased by the exogenous administration and protected the endothelial cells against $\mathrm{H}_{2} \mathrm{O}_{2}$ induced damage. The significantly increased levels in the patient group might be related to the compensation of the existing damage, but without a sufficient effect.

In conclusion, MDA levels were statistically and practically significant in the patient group than the control group in our study. As the mean age in the patient group was relatively higher and the patient group consisted only from those who were smokers or ex-smokers, a control group was formed consisting of healthy smokers aged $\geq 45$ years. The comparison of these two groups did not reveal no 
difference. The increased blood levels of MDA might be related to oxidative damage during the development of the disease. In the light of the results of the antioxidant enzyme measurements, we suggest that the significantly high GSH levels in the patient group were related to the compensation of the damage but were not sufficiently effective. However, the unchanged SOD levels, which is the first mechanism responsible for the compensation of oxidative damage, and the significantly low CAT levels might be related to the development of the disease. Further studies are needed to determine whether the low CAT levels caused by congenital or acquired factors.

\section{Declaration of conflicting interests}

The authors declared no conflicts of interest with respect to the authorship and/or publication of this article.

\section{Funding}

The authors received no financial support for the research and/or authorship of this article.

\section{REFERENCES}

1. Pincemail J, Defraigne JO, Cheramy-Bien JP, Dardenne N, Donneau AF, Albert A, et al. On the potential increase of the oxidative stress status in patients with abdominal aortic aneurysm. Redox Rep 2012;17:139-44.

2. Parastatidis I, Weiss D, Joseph G, Taylor WR. Overexpression of catalase in vascular smooth muscle cells prevents the formation of abdominal aortic aneurysms. Arterioscler Thromb Vasc Biol 2013;33:2389-96.

3. Rajagopalan S, Meng XP, Ramasamy S, Harrison DG, Galis ZS. Reactive oxygen species produced by macrophage-derived foam cells regulate the activity of vascular matrix metalloproteinases in vitro. Implications for atherosclerotic plaque stability. $J$ Clin Invest 1996;98:2572-9.

4. Li PF, Dietz R, von Harsdorf R. Reactive oxygen species induce apoptosis of vascular smooth muscle cell. FEBS Lett 1997;404:249-52.

5. Wiernicki I, Parafiniuk M, Kolasa-Wolosiuk A, Gutowska I, Kazimierczak A, Clark J, et al. Relationship between aortic wall oxidative stress/proteolytic enzyme expression and intraluminal thrombus thickness indicates a novel pathomechanism in the progression of human abdominal aortic aneurysm. FASEB J 2019;33:885-95.

6. Förstermann U, Xia N, Li H. Roles of Vascular Oxidative Stress and Nitric Oxide in the Pathogenesis of Atherosclerosis. Circ Res 2017;120:713-35.

7. McCormick ML, Gavrila D, Weintraub NL. Role of oxidative stress in the pathogenesis of abdominal aortic aneurysms. Arterioscler Thromb Vasc Biol 2007;27:461-9.
8. Nordon IM, Hinchliffe RJ, Loftus IM, Thompson MM. Pathophysiology and epidemiology of abdominal aortic aneurysms. Nat Rev Cardiol 2011;8:92-102.

9. Indes JE, Pfaff MJ, Farrokhyar F, Brown H, Hashim P, Cheung K, et al. Clinical outcomes of 5358 patients undergoing direct open bypass or endovascular treatment for aortoiliac occlusive disease: a systematic review and meta-analysis. J Endovasc Ther 2013;20:443-55.

10. Norgren L, Hiatt WR, Dormandy JA, Nehler MR, Harris KA, Fowkes FG, et al. Inter-society consensus for the management of peripheral arterial disease. Int Angiol 2007;26:81-157.

11. Weintraub NL. Understanding abdominal aortic aneurysm. N Engl J Med 2009;361:1114-6.

12. Aggarwal S, Qamar A, Sharma V, Sharma A. Abdominal aortic aneurysm: a comprehensive review. Exp Clin Cardiol 2011;16:11-5.

13. Sugamura K, Keaney JF Jr. Nicotine: linking smoking to abdominal aneurysms. Nat Med 2012;18:856-8.

14. Lindsay ME, Dietz HC. Lessons on the pathogenesis of aneurysm from heritable conditions. Nature 2011;473:308-16.

15. Lucas ML, Carraro CC, Belló-Klein A, Kalil AN, Aerts NR, Carvalho FB, et al. Oxidative Stress in Aortas of Patients with Advanced Occlusive and Aneurysmal Diseases. Ann Vasc Surg 2018;52:216-24.

16. Placer ZA, Cushman LL, Johnson BC. Estimation of product of lipid peroxidation (malonyl dialdehyde) in biochemical systems. Anal Biochem 1966;16:359-64.

17. Chavan S, Sava L, Saxena V, Pillai S, Sontakke A, Ingole D. Reduced glutathione: Importance of specimen collection. Indian J Clin Biochem 2005;20:150-2.

18. Góth L. A simple method for determination of serum catalase activity and revision of reference range. Clin Chim Acta 1991;196:143-51.

19. Sun Y, Oberley LW, Li Y. A simple method for clinical assay of superoxide dismutase. Clin Chem 1988;34:497-500.

20. Yiğit S, Mendeş $M$. Which effect size measure is appropriate for one-way and two-way ANOVA models? A monte carlo simulation study. REVSTAT 2018;16:295-313.

21. Forstermann U. Oxidative stress in vascular disease: causes, defense mechanisms and potential therapies. Nat Clin Pract Cardiovasc Med 2008;326:745-53.

22. Singh U, Jialal I. Oxidative stress and atherosclerosis. Pathophysiology 2006;13:129-42.

23. Miller FJ Jr, Sharp WJ, Fang X, Oberley LW, Oberley TD, Weintraub NL. Oxidative stress in human abdominal aortic aneurysms: a potential mediator of aneurysmal remodeling. Arterioscler Thromb Vasc Biol 2002;22:560-5.

24. Dubick MA, Keen CL, DiSilvestro RA, Eskelson CD, Ireton J, Hunter GC. Antioxidant enzyme activity in human abdominal aortic aneurysmal and occlusive disease. Proc Soc Exp Biol Med 1999;220:39-45.

25. Förstermann U. Nitric oxide and oxidative stress in vascular disease. Pflugers Arch 2010;459:923-39. 
26. Zhang J, Schmidt J, Ryschich E, Mueller-Schilling $\mathrm{M}$, Schumacher $\mathrm{H}$, Allenberg JR. Inducible nitric oxide synthase is present in human abdominal aortic aneurysm and promotes oxidative vascular injury. J Vasc Surg 2003;38:360-7.

27. Batatinha HAP, Rosa Neto JC, Krüger K. Inflammatory features of obesity and smoke exposure and the immunologic effects of exercise. Exerc Immunol Rev 2019;25:96-111.

28. Fukai T, Ushio-Fukai M. Superoxide dismutases: role in redox signaling, vascular function, and diseases. Antioxid Redox Signal 2011;15:1583-606.

29. Stocker R, Keaney JF Jr. Role of oxidative modifications in atherosclerosis. Physiol Rev 2004;84:1381-478.

30. Faraci FM, Didion SP. Vascular protection: superoxide dismutase isoforms in the vessel wall. Arterioscler Thromb Vasc Biol 2004;24:1367-73.

31. Li H, Horke S, Förstermann U. Vascular oxidative stress, nitric oxide and atherosclerosis. Atherosclerosis 2014;237:208-19.

32. Li Y, Huang TT, Carlson EJ, Melov S, Ursell PC, Olson JL, et al. Dilated cardiomyopathy and neonatal lethality in mutant mice lacking manganese superoxide dismutase. Nat Genet 1995;11:376-81.

33. Lucas ML, Carraro CC, Belló-Klein A, Kalil AN, Aerts N. Oxidative stress in human aorta of patients with advanced aortoiliac occlusive disease. Braz J Cardiovasc Surg 2016;31:428-33.

34. Öztürel A. Ölüm zamanı tayininde kullanılan metotlar. http://dergiler.ankara.edu.tr/dergiler/38/342/3528.pdf

35. Yajima N, Masuda M, Miyazaki M, Nakajima N, Chien S, Shyy JY. Oxidative stress is involved in the development of experimental abdominal aortic aneurysm: a study of the transcription profile with complementary DNA microarray. J Vasc Surg 2002;36:379-85.

36. Kugo H, Miyamoto C, Sawaragi A, Hoshino K, Hamatani Y, Matsumura S, et al. Sesame Extract Attenuates the Degradation of Collagen and Elastin Fibers in the Vascular Walls of Nicotine-administered Mice. J Oleo Sci 2019;68:79-85.

37. Yang H, Roberts LJ, Shi MJ, Zhou LC, Ballard BR, Richardson A, et al. Retardation of atherosclerosis by overexpression of catalase or both $\mathrm{Cu} / \mathrm{Zn}$-superoxide dismutase and catalase in mice lacking apolipoprotein E. Circ Res 2004;95:1075-81.

38. Kattoor AJ, Pothineni NVK, Palagiri D, Mehta JL. Oxidative Stress in Atherosclerosis. Curr Atheroscler Rep 2017;19:42.

39. Yang $H$, Zhou L, Wang Z, Roberts LJ, Lin X, Zhao Y, et al. Overexpression of antioxidant enzymes in ApoEdeficient mice suppresses benzo(a)pyrene-accelerated atherosclerosis. Atherosclerosis 2009;207:51-8.

40. Meister A, Anderson ME. Glutathione. Annu Rev Biochem 1983;52:711-60.

41. Tsan MF, White JE, Rosano CL. Modulation of endothelial GSH concentrations: effect of exogenous GSH and GSH monoethyl ester. J Appl Physiol (1985) 1989;66:1029-34. 